\title{
A BRIEF REVIEW OF METHODS FOR INCREASING THE SERVICE LIFE OF LASER METAL OPTICS
}

\author{
S. A. Filin ${ }^{1}$, V. E. Rogalin ${ }^{2,3}$, I. A. Kaplunov ${ }^{3}$, S. A. Tretiakov ${ }^{3}$ \\ ${ }^{1}$ Plekhanov National University of Economics, \\ 36, Stremyannyj Lane, 117997, Moscow, Russian Federation \\ ${ }^{2}$ Astrofizika National Center of Laser Systems and Complexes JSC, \\ 95, Volokolamskoe Hwy., 125424, Moscow, Russian Federation \\ ${ }^{3}$ Tver State University, 33, Zhelyabova St., 170100, Tver, Russian Federation \\ *Corresponding author. E-mail: Kaplunov.IA@tversu.rul.ru \\ Address for correspondence: 33, Zhelyabova St., 170100, Tver, Russian Federation \\ Tel.: +7 (4822) 3228 39; fax: +7 (4822) 322839
}

The experience gained during the operation of laser metal optics required a new approach to the technology of preparing mirrors. The operational properties of mirrors directly depend on the energy state of the surface described by such parameters as reflection coefficient, roughness, optical purity, adhesion durability, threshold optical breakdown, etc. Cleaning and/or modification of the surface affect these properties actively, since a surface layer with charged inside technological impurities is formed during the manufacture of mirrors. This layer differs in structure and properties from the bulk of the material significantly. When choosing a detergent medium, it is necessary to take into account the increased chemical activity of the surface in view of the properties of the metal, as well as the necessity of preserving the optical parameters of the surface after cleaning and/or surface modification. Oxygen-free metal surfaces are more difficult to clean in the case of complex contamination; however, in the overwhelming majority of cases, when cleaning metal optics, we have to deal with an oxide-covered surface.

Keywords: laser, cleaning of a surface, metal mirror, technological contaminations, adhesive durability, threshold optical damage.

DOI: $10.17804 / 2410-9908.2017 .4 .044-051$

\section{References}

1. Zimon A.D. Adgeziya plenok $i$ pokrytiy [Adhesion of Films and Coatings]. M., Khimiya Publ., 1977, 352 p. (In Russian).

2. Itogi nauki i tekhniki. Seriya: Radiotekhnika [R.G. Mirimanova, ed. Summary of Science and Technology]. M., VINITI Publ., 1983, vol. 31, 219 p. (In Russian).

3. Mann J.B., Ogata R., Hagakawa T. Recent Developments in Mass Spectrometry, Tokio, University Press, $1980,814 \mathrm{p}$.

4. Filin S.A., Rogalin V.E., Kaplunov I.A. Fiziko-khimicheskaya ochistka poverkhnosti silovoy metallooptiki s tselyu uvelicheniya opticheskoy stoykosti. In: Sbornik nauchnykh statey III Mezhdunarodnoy nauchno-prakticheskoy konferentsii «Fizika $i$ tekhnologiya nanomaterialov i struktur» [Physics and Technology of Nanomaterials and Structures: Proceedings of the Third International Scientific and Practical Conference]. Kursk, Universitetskaya Kniga Publ., 2017, pp. 349-357. (In Russian).

5. Arkhipov Yu.V., Belashkov I.N., Datskevich N.P., Egorov V.N., Izyumov A.F., Karlov N.V., Konov V.I., Kononov N.N., Kuz'min G.P., Nesterenko A.A., Chapliev N.I. Thresholds of the optical-breakdown in air on a polished metal-surface for the radiation at lambda=10.6-mu-m. Kvantovaya Elektronika, 1986, vol. 13, no. 1, pp. 103-109.

6. Rogalin V.E. Effect of Absorbing Microinhomogeneities on Optical Damage to AlkaliHalide Crystals. Bulletin of the Russian Academy of Sciences: Physics, 2012, vol. 76, no. 11, pp. 1205-1216. DOI: $10.3103 / \mathrm{S} 1062873812110184$. 
7. Rogalin V.E. Optical durability of copper mirrors for powerful impulse TEA $\mathrm{CO}_{2}$ lasers. Materialovedenie, 2013, no. 9, pp. 34-42. (In Russian).

8. Rogalin V.E., Kaplunov I.A. Optical properties of metal mirrors for $\mathrm{CO}_{2}$ lazers. Izvestiya Sochinskogo gosudarstvennogo universiteta, 2013, nos. 4-2 (28), pp. 120-127.

9. Luft B.D., Shustina A.L. Ochistka detaley elektronnykh priborov [Cleaning of Parts of Electronic Devices]. M., Energiya Publ., 1968, 320 p. (In Russian).

10. Dong Guojun, Grubyj S.V Study of regularities in process of diamond turning and accuracy of processing the surfaces of metal optics. Tekhnologiya metallov, 2008, no. 2, pp. 26-32. (In Russian).

11. Drobot A.D., Ilin M.K., Rogalin V.E., Filin S.A., Jampolskij V.I., Narusbek Eh.A. Method for cleaning optical surface of products from metal and alloys. RF Patent 2049155, 1995. (In Russian).

12. Drobot A.D., Ilin M.K., Rogalin V.E., Filin S.A., Jampolskij V.I. Process of purifying surface of objects of metals and their alloys. RF Patent 2070621, 1996. (In Russian).

13. Filin S.A., Ilyin M.K., Yampolsky V.I. A method for purifying the optical surface of copper and copper alloy products. $R F$ Patent 2091505, 1997. (In Russian).

14. Kaplunov I.A., Rogalin V.E., Filin S.A. Research of possibility of laser-chemical purification of metallic surfaces. Tsvetnye metally, 2015, no. 1, pp. 29-31. (In Russian).

15. Semenov A.P. Trenie i kontaktnoe vzaimodeistvie grafita i almaza s metallami i splavami [Friction and Contact Interaction of Graphite and Diamond with Metals and Alloys]. M., Nauka Publ., 1974, 236 p. (In Russian).

16. Yatseritsyn A.P., Tsokur A.K., Eremenko A.L. Teplovye yavleniya pri shlifovanii i svoystva obrabotannykh poverhnostey [Thermal Phenomena in Polishing and the Properties of the processed Surfaces]. Minsk, Nauka i Tekhnika Publ., 1973, 212 p. (In Russian).

17. Examining Surfaces of Oxidized Aluminum Exposed to $\mathrm{CO}_{2}$ Laser Pulses. Bulletin of the Russian Academy of Sciences: Physics, 2016, vol. 80, no. 12, pp. 1489-1493. DOI 10.3103/S1062873816120170.

18. Kurs fizicheskoy khimii [Ya.A. Gerasimov, ed. The Course of Physical Chemistry]. M., Khimiya Publ., 1973, vol. 2, 623 p. (In Russian). 
Подана в журнал: 29.06 .2017

УДК 539.4.015.2; 684.4.059.8

DOI: $10.17804 / 2410-9908.2017 .4 .044-051$

\title{
КРАТКИЙ ОБЗОР МЕТОДОВ ПОВЫШЕНИЯ РЕСУРСА ЛАЗЕРНОЙ МЕТАЛЛООПТИКИ
}

\author{
С. А. Филин ${ }^{1}$, В. Е. Рогалин ${ }^{2,3}$, И. А. Каплунов ${ }^{3}$, С. А. Третьяков ${ }^{3}$ \\ ${ }^{1}$ Российский экономический университет им. Г.В. Плеханова \\ 117997, Стремянный пер., 36, Москва, Российская Федерация \\ ${ }^{2}$ АО «Национальный центр лазерных систем и комплексов «Астрофизика» \\ 125424, Волоколамское ш., 95, Москва, Российская Федераџия \\ ${ }^{3}$ Тверской государственный университет \\ 170100, ул. Желябова, 33, Тверь, Российская Федерация
}

\author{
*Ответственный автор. Электронная почта: Kaplunov.IA@tversu.rul.ru \\ Адрес для переписки: 170100, г. Тверь, ул. Желябова, 33 \\ Тел.: +7 (4822) 32-28-39; факс: +7 (4822) 32-28-39
}

Опыт эксплуатации лазерной металлооптики потребовал нового подхода к технологии подготовки зеркал. Эксплуатационные свойства зеркал напрямую зависят от энергетического состояния поверхности, описываемого такими параметрами, как коэффициент отражения, шероховатость, оптическая чистота, адгезионные свойства, порог оптического пробоя и т. д. Очистка и (или) модификация поверхности активно влияют на эти свойства, так как при изготовлении зеркал образуется поверхностный слой с зашаржированными технологическими примесями. Этот слой заметно отличается по структуре и свойствам от объема материала. При выборе моющей среды следует учитывать повышенную химическую активность поверхности с учетом свойств металла, а также необходимость сохранения оптических параметров поверхности после очистки и (или) модификации поверхности. Освобожденные от оксидов поверхности металлов труднее поддаются очистке при комплексном загрязнении, но в подавляющем большинстве случаев при очистке металлооптики приходится иметь дело с поверхностью, покрытой оксидом.

Ключевые слова: лазер, очистка поверхности, металлическое зеркало, технологические загрязнения, адгезионная прочность, порог оптического пробоя.

\section{1. Введение}

Развитие лазерной металлооптики потребовало нового подхода к технологии подготовки зеркал к эксплуатации. Ресурс зеркал связан с ужесточением требований к оптическим параметрам, связанным с энергетическим состоянием поверхности, таким как коэффициент отражения, шероховатость, оптическая чистота, адгезионные свойства, порог оптического пробоя и т. д.

Одним из основных процессов, влияющих на указанные свойства, является очистка оптической поверхности и ее модификация с целью достижения оптимальных эксплуатационных параметров. Связано это с тем, что в процессе изготовления зеркал образуется поверхностный слой, включающий в себя зашаржированные технологические примеси. Этот слой заметно отличается по структуре и свойствам от объема материала. Исследования [1-8] в области оптического материаловедения показали непосредственную зависимость важнейших эксплуатационных характеристик от оптических свойств поверхностного слоя, наличия в нем примесей.

Последние приводят к уменьшению адгезионной прочности наносимых покрытий, значительно снижают порог оптического пробоя (под действием лазерного излучения проис- 
ходит выгорание (взрывного типа) примесей и разрушение поверхности при мощностях потока гораздо ниже расчетных) [2, 4-8], а также ухудшают другие оптические параметры: чистоту, коэффициент отражения, механическую прочность покрытий, коррозионную стойкость и т. п.

\section{2. Постановка задачи и методы решения}

По данным анализа требований к надежности современных приборов с большим сроком службы [9] считается, что количество органических загрязнений на рабочей поверхности

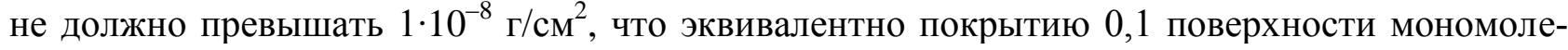
кулярным слоем стеариновой кислоты, принятой при исследовании ряда процессов очистки в качестве модельного загрязнения; солями (хлоридами, сульфидами, фосфатами и т. д.) $1 \cdot 10^{-8}-1 \cdot 10^{-9} \Gamma / \mathrm{cm}^{2}$. Для оптической поверхности, подвергающейся воздействию высокоэнергетического, например лазерного, излучения, количество загрязнений не должно превышать $1 \cdot 10^{-9}-1 \cdot 10^{-10} \mathrm{\Gamma} / \mathrm{cm}^{2}$.

С точки зрения проблемы получения поверхности металла такого уровня чистоты представляют интерес следующие ее свойства: оптические характеристики (коэффициент отражения, шероховатость, оптическая чистота, адгезионные свойства, порог оптического пробоя и т.д.), наличие оксида на поверхности и его тип, наличие в оптическом поверхностном слое примесей, чувствительность металла к коррозионному воздействию моющей среды, неоднородность химической активности, геометрическая форма и габаритные размеры поверхности.

Резка металлических слитков на пластины сопровождается интенсивным механическим воздействием на поверхность и придает ей значительные нарушения и определенную степень шероховатости. Последующие процессы чистового шлифования и окончательного полирования свободным абразивом, применяющиеся для придания металлооптическим элементам требуемых размеров, точных геометрических параметров (плоскостности и параллельности) и оптической чистоты поверхности, также формируют нарушенный слой. По существу метод основан на взаимном притирании инструмента и детали через слой абразивной суспензии. При полировке обрабатываемая поверхность обычно соприкасается с инструментом - мягким веществом, типа полировальной смолы, кожи или ткани. Абразив, поддерживаемый мягкой поверхностью, не царапает обрабатываемую поверхность, а вызывает за счет пластической деформации вязкое течение материала поверхности. Однако на качество поверхностного слоя отрицательно влияет шаржирование абразивными микрочастицами и загрязнение поверхности полировальным составом.

Позднее появился метод лезвийной обработки - алмазное точение как метод автоматизированной обработки поверхностей металлооптики алмазными монокристаллическими резцами на специальных особо точных прецизионных станках [10]. В этом случае степень повреждения поверхностного слоя минимизируется. При алмазном точении даже крупногабаритных металлооптических элементов достигается точность обработки от 0,5 до 0,025 мкм со средней квадратичной величиной микронеровностей менее 10 нм. Однако и в случае алмазного точения процесс может завершаться как с последующей операцией полирования абразивным инструментом, так и без нее, например, для алюминиевого сплава АМг6, эксплуатируемого в лазерах ИК-области спектра.

Однако во всех случаях получения металлооптики, а также при последующей эксплуатации этих зеркал, на оптической поверхности появляются технологические и иные загрязнения, ухудшающие оптические свойства металлооптики и, как следствие, требующие очистки оптической поверхности от таких загрязнений [11-14]. В свою очередь очистка такого специфического с точки зрения твердости химической активности и оптических свойств материала, как металл, требует обоснования подходов и методов к очистке и (или) модифи- 
кации оптической поверхности от загрязнений, обеспечивающих улучшение ее эксплуатационных свойств.

\section{3. Результаты и обсуждение}

Предполагается, что в металлических монокристаллах нарушенный слой после процесса полирования можно разделить на следующие различные по характеру зоны (рис. 1): аморфная зона, аморфная зона с трещинами, деформированная зона с повышенной плотностью дислокаций.

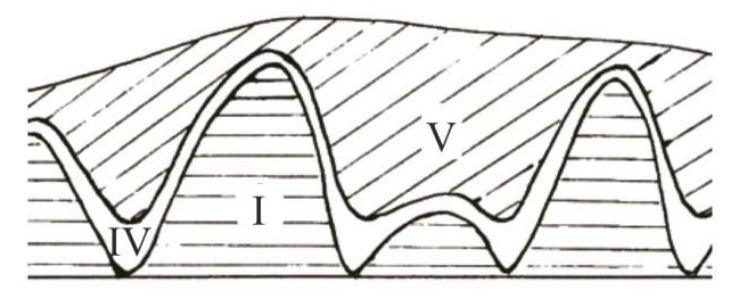

II

III

Рис. 1. Зоны слоев с нарушенной монокристалличностью:

I - аморфная зона; II - аморфная зона с трещинами; III - деформированная зона

с повышенной плотностью дислокаций; IV - оксидный слой; V - слой загрязнений

В аморфной зоне образуется слой оксида, на котором присутствуют загрязнения (наиболее чистые поверхности получаются при раскалывании монокристаллов). Аморфная зона (как её часто называют «слой Бэйлби»), как правило, имеет глубину $30 \AA$ [10]. Деформированная зона с повышенной плотностью дислокаций (слой III) является переходной от аморфной структуры к ненарушенному монокристаллу и содержит механические напряжения, а в некоторых случаях и микротрещины. Величина нарушенного слоя может составлять десятки микрометров.

Аморфная зона обладает свойствами, резко отличающимися от свойств недеформированной зоны металла: она гораздо тверже, обычно более растворима и электрохимически отрицательна, что стимулирует коррозию металла, часто начинающейся в местах, где имело место поверхностное течение или какое-либо иное нарушение кристаллической структуры, например вблизи углубления или отверстия. Теплота растворения поверхностных слоев полированного металла меньше, чем неполированной, что указывает на накопление в поверхностных слоях избыточной свободной энергии.

Контактному взаимодействию с металлами и сплавами полирующих порошков, в том числе при высоких температурах, посвящены работы $[15,16]$. Механизм образования аморфного поверхностного слоя представляется комбинацией многих процессов. В металле возникают значительные напряжения сдвига, вызывающие скольжение вдоль плоскостей структуры монокристаллических зёрен и его пластическую деформацию, а затем и разрушение. В случае более острых выступов разрушение может возникать и при сжатии. При этом на поверхности образуются продукты износа абразива в виде мелкодисперсных включений. При полировании поверхностные слои в отдельных точках могут претерпевать мгновенные акты плавления, обусловленные взаимодействием с полирующим материалом (шероховатость контактирующих тел по высотным параметрам больше или меньше в 1,5-10 раз, кон- 
такт происходит при скольжении в широком диапазоне скоростей $-0,5-100 \mathrm{~m} / \mathrm{c})$. В месте контакта поверхности металла с абразивом возникают температуры в диапазоне 50-1600 ${ }^{\circ} \mathrm{C}$ [15], быстро повышающиеся до температуры плавления металла, если она входит в этот диапазон.

Степень нарушения структуры металла постепенно изменяется при переходе от поверхности к более глубоким слоям. Под аморфным поверхностным слоем расположены слои с постепенно увеличивающимися размерами монокристаллических зёрен, а на глубине нескольких микрометров (может быть и больше) наблюдается исходная структура.

Полированная поверхность имеет определенную шероховатость, средние размеры которой обусловлены как размером и ориентацией монокристаллических зёрен, так и полирующим материалом, режимом и длительностью обработки, применёнными в процессе полировки особенно на последней стадии - доводке, и составляет $\sim R_{\mathrm{z}}=0,01-0,05$ мкм. Шероховатость способствует скоплению загрязнений, например, масляных соединений. С ростом шероховатости методы определения чистоты поверхности становятся менее надежными.

Все металлы покрыты пленкой оксидов. Кривые кинетики химической коррозии меди, широко применяющейся для создания металлооптики, показывают рост оксидной пленки в зависимости от времени выдержки при различных условиях, в частности, до значительной величины в течение нескольких секунд (рис. 2).

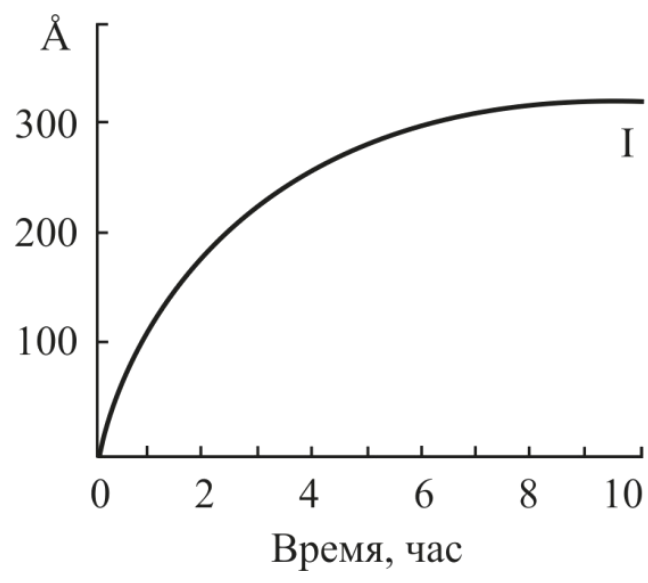

$a$

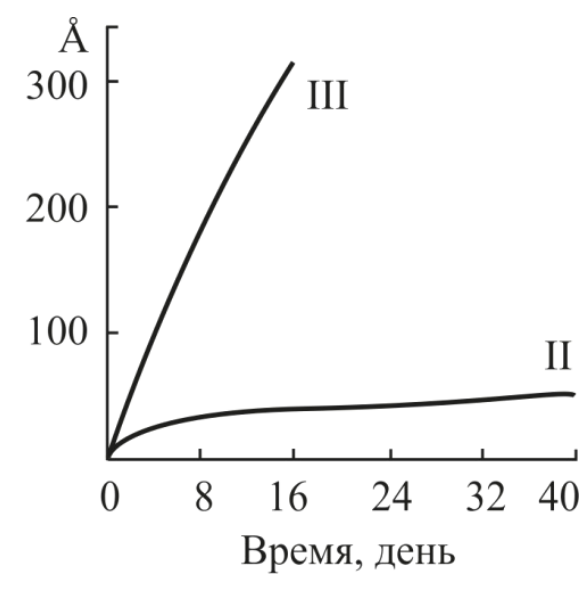

$\sigma$

Рис. 2. Нарастание слоя оксида меди от времени выдержки: $a-\mathrm{I}$ в воздухе при $100{ }^{\circ} \mathrm{C}$; $\sigma$ - II в открытом сосуде при $20{ }^{\circ} \mathrm{C}$ и III в эксикаторе над $\mathrm{P}_{2} \mathrm{O}_{5}$ при $20{ }^{\circ} \mathrm{C}$

Прочность сцепления загрязнения с поверхностью зависит от типа их взаимодействия. Минеральные масла прочнее удерживаются на свободной от оксида поверхности (межмолекулярное взаимодействие), жирные кислоты прочнее удерживаются на поверхности оксида (химическая связь). Меньшее сцепление неполярного минерального масла с оксидом объясняется формированием между ними дисперсионного взаимодействия, с кислотами возникает химическая связь.

Чувствительность (сенсибилизация) металлов к агрессивному воздействию моющих сред оказывает существенное влияние на выбор моющей среды и режимы очистки. Например, сенсибилизация алюминия, также широко применяемого для изготовления зеркал, обусловлена образованием мельчайших трещин в слое оксида [17], который обычно защищает металл от коррозии. Точечная коррозия может произойти именно на этих участках. Сенсибилизацию обуславливают факторы: 1) атмосферное воздействие, когда при наличии в воздухе влажного электролита возникают локальные гальванические эффекты; 2) кислотные испарения, являющиеся причиной высокой сенсибилизации алюминия, если металл хранится в местах с высоким насыщением воздуха парами кислот, особенно соляной, при этом гальваническое воздействие усиливает этот процесс; 3) химическое взаимодействие с агрессивными 
для данного металла растворителями, вызывающими его коррозию, в том числе взаимодействие с продуктами разложения растворителей, например, термического при длительной эксплуатации, даже если моющая среда не оказывает такого воздействия (вторичный эффект). Последний фактор требует использования стабильного при длительном использовании растворителя.

Сенсибилизация меди и ее сплавов заключается в том, что они быстро тускнеют при нагревании и увлажнении на воздухе.

Неоднородность химической активности поверхности металлов, как правило, обусловлена наличием энергетически активных центров, обладающих максимальной энергией адсорбции, на которые и приходится основная масса адсорбированного вещества (количество этих центров невелико). Поэтому, искусственно снижая энергию адсорбции этих активных центров соединениями, которые впоследствии легко удаляются или не оказывают отрицательного воздействия на эксплуатационные характеристики оптических элементов, можно значительно снизить энергию адсорбции трудноудалимых загрязнений и, как следствие, их массу на оптической поверхности. Примером соединения, снижающего энергию адсорбции наиболее энергетически активных центров на оптической поверхности, является оксид углерода, искусственно предварительно и/или после процесса очистки адсорбированный на поверхность меди [18].

\section{4. Заключение}

При выборе моющей среды, режимов обработки и длительности использования моющей среды следует учитывать повышенную химическую активность полированной поверхности с учетом свойств соответствующего металла, а также необходимость сохранения оптических параметров поверхности в процессе очистки.

В общем случае, освобожденные от оксидов поверхности металлов труднее поддаются очистке при комплексном загрязнении различного типа. В подавляющем большинстве случаев при очистке металлооптики приходится иметь дело с поверхностью, покрытой оксидом.

\section{Благодарность}

Работа выполнена в рамках проекта РФФИ по теме «Влияние социокультурной среды на формирование научного потенциала современного ученого-исследователя в России и Монголии», номер проекта 17-23-03003.

\section{Литература}

1. Зимон А. Д. Адгезия пленок и покрытий. - М. : Химия, 1977. - 352 с.

2. Итоги науки и техники. Серия: Радиотехника / под общ. ред. Р. Г. Мириманова. Т. 31. - М. : ВИНИТИ, 1983. - 219 с.

3. Mann J. B., Ogata R., Hagakawa T. Recent Developments in Mass Spectrometry. - Tokyo : University Press, 1980. -814 c.

4. Филин С. А., Рогалин В. Е., Каплунов И. А. Физико-химическая очистка поверхности силовой металлооптики с целью увеличения оптической стойкости // 3-я Международная научно-практическая конференция «Физика и технология наноматериалов и структур», Курск, 23-25 мая 2017 г. : сборник научных статей : в 2-х т. - Курск : Университетская книга, 2017. - C. 349-357.

5. Пороги оптического пробоя воздуха на полированной металлической поверхности для излучения с $\lambda=10,6$ мкм / Ю. В. Архипов, И. Н. Белашков, И. П. Дацкевич, В. Н. Егоров, А. Ф. Изюмов, Н. В. Карлов, В. И. Конов, Н. Н. Кононов, Г. П. Кузьмин, А. А. Нестеренко, Н. И. Чаплиев // Квантовая электроника. - 1986. - Т. 13, № 1. - С. 103-109. 
6. Rogalin V. E. Effect of Absorbing Microinhomogeneities on Optical Damage to AlkaliHalide Crystals. - Bulletin of the Russian Academy of Sciences: Physics. - 2012. - Vol. 76, no. 11. P. 1205-1216. - DOI: 10.3103/S1062873812110184.

7. Рогалин В. Е. Оптическая стойкость медных зеркал для мощных импульсных ТЕА $\mathrm{CO}_{2}$-лазеров // Материаловедение. - 2013. - № 9. - С. 34-42.

8. Рогалин В. Е., Каплунов И. А. Оптические свойства металлических зеркал для $\mathrm{CO}_{2}$-лазеров // Известия Сочинского государственного университета. - 2013. - № 4-2 (28). C. $120-127$.

9. Луфт Б. Д., Шустина А. Л. Очистка деталей электронных приборов. - М. : Энергия, 1968. - $320 \mathrm{c}$.

10. Дун Гоцзюнь, Грубый С. В. Анализ закономерностей процесса алмазного точения и точности обработки поверхностей металлооптики // Технология металлов. - 2008. - № 2. C. $26-32$.

11. Способ очистки оптической поверхности изделий из металлов и их сплавов : пат. 2049155 Рос. Федерация / Дробот А. Д., Ильин М. К., Рогалин В. Е., Филин С. А., Ямпольский В. И., Нарусбек Э. А. - № 3136451/26 ; заявл. 07.03.1986 ; опубл. 27.11.1995, Бюл. № 33 .

12. Способ очистки поверхности изделий из металлов и их сплавов : пат. 2070621 Рос. Федерация / Дробот А. Д., Ильин М. К., Рогалин В. Е., Филин С. А., Ямпольский В. И. № 4520386/02 ; заявл. 13.09.1989, Бюл. № 35 .

13. Способ очистки оптических изделий из меди и ее сплавов : пат. РФ 2091505 Рос. Федерация / Ильин М. К., Филин С. А., Ямпольский В. И. - № 3199964/25 ; заявл. 20.05.1988 ; опубл. 27.09.1997, Бюл. № 27.

14. Каплунов И. А., Рогалин В. Е., Филин С. А. Исследование возможности лазернохимической очистки металлических поверхностей // Цветные металлы. - 2014. - № 7 . С. $72-75$.

15. Семенов А. П. Трение и контактное взаимодействие графита и алмаза с металлами и сплавами. - М. : Наука, 1974. - 236 с.

16. Яцерицын А. П., Цокур А. К., Еременко А. Л. Тепловые явления при шлифовании и свойства обработанных поверхностей. - Минск : Наука и техника, 1973. -212 с.

17. Исследование поверхности оксидированного алюминия после воздействия импульса $\mathrm{CO}_{2}$-лазера / В. Е. Рогалин, О. М. Кугаенко, Е. Е. Ашкинази, М. С. Андреева, С. А. Филин // Известия РАН. Сер. физ. - 2016. - Т. 80, № 12. - С. 1688-1692. DOI: $10.7868 / \mathrm{S} 0367676516120176$.

18. Курс физической химии / под общ. ред. Я. А. Герасимова. - Т. 2. - М. : Химия, 1973.$623 \mathrm{c}$. 